\title{
The Medical Effects of Seat-Belt Legislation in the United Kingdom: a critical review of the findings
}

\author{
W. H. RUTHERFORD \\ Accident and Emergency Department, Royal Victoria Hospital, Belfast, Northern Ireland
}

In attempting to review the research report critically, there must be one main caveat: there is a danger after a large amount of information has been coded and entered into a computer that the output may give a false appearance of certainty. The most vital items of information in this study are those related to diagnosis, which is, in part, a matter of subjective judgement. As well as this basic caveat, two hypotheses should be mentioned, which, regrettably, were not made. Firstly, it should have been predicted that because seat-belts prevent injuries, belt-wearing rates among patients would be lower than rates for motorists in the community. It was also predictable that as wearing rates for motorists approached $100 \%$ after legislation, the difference between wearing rates for patients and for motorists would get less. All these effects were demonstrated in the findings, and-even without prediction-are still evidence of the effectiveness of the belt, a piece of evidence not readily available from most of the other studies.

A further regret is that information was not collected about the type and speed limits of roads where the accidents occurred.

Undoubtedly, the report provides evidence that the seat-belt legislation was effective. However, that judgement can probably be better made from an examination of national trafficcasualty statistics. The particular value of this report is that it shows not only that the legislation is effective, but how it is effective. It distinguishes not only differences in injuries to drivers, frontseat passengers and rear-seat passengers, but exactly in which body region and which organs within the body regions the injuries were sustained.

For example, Table 1 shows the effects of the legislation on a wide selection of injuries to the heads of front-seat passenger patients. For all these injuries, a reduction in numbers occurred. By contrast, driver patients, while showing a decline for minor brain injuries, wounds and contusions of the face, and eye injuries, showed increases in major brain injuries, scalp contusions and facial fractures. This was because inertia reel belts may, at certain speeds, facilitate contact between the head and the steering wheel.

Table 1 Head injuries (patients)

\begin{tabular}{lrrrrrr}
\hline & $D 1$ & $D 2$ & + or - & FSP1 & FSP2 & + or - \\
\hline Minor brain injuries & 606 & 399 & - & 296 & 124 & - \\
Major brain injuries & 32 & 46 & + & 22 & 13 & - \\
Wounds (face) & 1101 & 617 & - & 553 & 206 & - \\
Contusions (face) & 662 & 292 & - & 387 & 81 & - \\
Contusions (scalp) & 142 & 180 & + & 51 & 50 & - \\
Eye injuries & 98 & 61 & - & 59 & 32 & - \\
Fractures (face) & 134 & 149 & + &
\end{tabular}

D1 $=$ Drivers in first year

D2 $=$ Drivers in second year

FSP1 = Front-seat passengers in first year

FSP2 $=$ Front-seat passengers in second year

Correspondence: $M r W . H$. Rutherford, Accident and Emergency Department, Royal Victoria Hospital, Belfast, $B T 12$ 6BA, Northern Ireland 


\section{$222 W$. H. Rutherford}

Table 2 shows the number of fatalities who sustained various thoracic injuries. These are in line with, but more comprehensive than, those for patients. They show improvements for injuries to $\frac{3}{8}$ lungs, heart, aorta, ribs and sternum. Among patients there was one striking difference: fractured. sternum increased by over $100 \%$.

In cases of abdominal injury there appears to be a marked decline in fatalities from liver and $\stackrel{\vec{F}}{\stackrel{\vec{f}}{\circ}}$ spleen injuries. Kidney injuries also appear to have fallen among patients, but injuries of the $\frac{C}{0}$ gastrointestinal tract seem to have increased (Table 2).

Table 2 Injuries of thorax, abdomen, extremities and spine (patients and fatalities)

\begin{tabular}{|c|c|c|c|c|c|}
\hline $\begin{array}{l}\text { Patients/ } \\
\text { Fatalities }\end{array}$ & Region & Organ & FSO1 & $\mathrm{FSO} 2$ & $\overrightarrow{0}$ \\
\hline Fatalities & Thorax & $\begin{array}{l}\text { Lungs and pleura } \\
\text { Heart } \\
\text { Aorta } \\
\text { Ribs (fractures) } \\
\text { Sternum (fractures) }\end{array}$ & $\begin{array}{r}92 \\
21 \\
20 \\
101 \\
16\end{array}$ & $\begin{array}{r}65 \\
14 \\
15 \\
70 \\
4\end{array}$ & 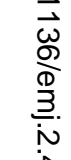 \\
\hline Fatalities & Abdomen & $\begin{array}{l}\text { Liver } \\
\text { Spleen }\end{array}$ & $\begin{array}{l}33 \\
23\end{array}$ & $\begin{array}{l}14 \\
15 \\
\end{array}$ & 1 \\
\hline Patients & Abdomen & $\begin{array}{l}\text { Stomach/intestine } \\
\text { Kidney }\end{array}$ & $\begin{array}{r}3 \\
42 \\
\end{array}$ & $\begin{array}{l}10 \\
24\end{array}$ & (1) \\
\hline Patients & Extremities & $\begin{array}{l}\text { Femur } \\
\text { Clavicle } \\
\text { Humerus } \\
\text { Radius/ulna }\end{array}$ & $\begin{array}{r}113 \\
80 \\
54 \\
150\end{array}$ & $\begin{array}{l}86 \\
61 \\
39 \\
81 \\
\end{array}$ & $\frac{\overparen{D}}{3}$ \\
\hline Patients & Spine & $\begin{array}{l}\text { Cervical fracture } \\
\text { Thoracic fracture } \\
\text { Lumbar fracture } \\
\text { Cervical sprain } \\
\text { Lumbar sprain }\end{array}$ & $\begin{array}{r}35 \\
19 \\
18 \\
1056 \\
30\end{array}$ & $\begin{array}{r}29 \\
20 \\
18 \\
1247 \\
97\end{array}$ & 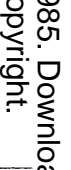 \\
\hline Fatalities & Spine & $\begin{array}{l}\text { Cervical fracture } \\
\text { Thoracic fracture } \\
\text { Lumbar fracture }\end{array}$ & $\begin{array}{l}9 \\
6 \\
0\end{array}$ & $\begin{array}{r}18 \\
14 \\
1\end{array}$ & 응 \\
\hline
\end{tabular}

In the extremities, there appear to have been fewer fractures of the femur, and all the long bones of the shoulder girdle, arm and forearm among patients (Table 2). There were not the same reductions among fatalities.

Among patients there was little change in spinal fractures, but there were increased sprains in 8 both cervical and lumbar regions. Among fatalities fractures of the cervical and thoracic region appear to have increased considerably (Table 2).

As far as patients are concerned, while the improvement for the driver has been very $\rightarrow$ satisfactory the improvement for the front-seat passenger was almost twice as good (Table 3). Table 4 shows that for fatalities, drivers obtained more benefit than front-seat passengers. ON

Table 3 Patients-non-admissions, admissions and bed-days/drivers and front-seat passengers

\begin{tabular}{lrrcrrrr}
\hline & \multicolumn{1}{c}{$D 1$} & \multicolumn{1}{c}{ D2 } & Change $(\%)$ & FSP1 & FSP2 & Change $(\%)$ \\
\hline Non-admissions & 3199 & 2868 & $-10 \cdot 3$ & 1604 & 1253 & $-21 \cdot 9$ & 0 \\
Admissions & 895 & 697 & $-22 \cdot 1$ & 458 & 264 & $-42 \cdot 4$ & 0 \\
Bed-days & 8814 & 6468 & $-26 \cdot 7$ & 4272 & 2794 & $-34 \cdot 6$ & $\%$ \\
\hline
\end{tabular}


Table 4 Fatalities: number of injuries by severity/drivers and front-seat passengers

\begin{tabular}{lrrcrcc}
\hline & $D 1$ & $D 2$ & Change (\%) & FSP1 & FSP2 & Change (\%) \\
\hline AIS1 & 374 & 248 & $-33 \cdot 7$ & 150 & 132 & $-12 \cdot 0$ \\
AIS2 & 193 & 108 & $-44 \cdot 0$ & 53 & 71 & $+34 \cdot 0$ \\
AIS3 & 145 & 106 & $-26 \cdot 9$ & 84 & 69 & $-17 \cdot 9$ \\
AIS4 & 70 & 42 & $-40 \cdot 0$ & 32 & 27 & $-15 \cdot 6$ \\
AIS5 & 46 & 32 & $-30 \cdot 4$ & 17 & 19 & $+11 \cdot 8$ \\
AIS6 & 8 & 7 & $\star$ & 4 & 9 & $\star$ \\
\hline
\end{tabular}

* Numbers too small to yield a meaningful figure

Some of the injuries shown in these tables were neither the subject of a hypothesis, nor have they reached a significant $p$ value. However; the overall picture presented seems both reasonably accurate and consistent with previous studies on the effects of seat-belts on particular organs. By including both proven changes and appearances which seem reasonably likely to have been influenced by belt wearing, a more complete although, in some aspects, tentative picture of the overall effect of the belt emerges. From this it is possible to speculate on belt modifications and other safety devices by which morbidity and mortality may be even further reduced.

This is not the place to advise on the exact types of safety devices which should be used. However, from the picture that has emerged of changes in organ injury pattern, a number of objectives can be seen:

- to hold the driver off the steering wheel and, in particular, to hold the driver's head off the steering wheel;

- to reduce fractures of the sternum;

to prevent ruptures of the gastrointestinal tract;

- to prevent sprains of the lumbar spine and fractures of the thoracic spine;

- to prevent sprains and fractures of the cervical spine;

- to obtain for rear-seat passengers the same benefits already achieved for front-seat occupants. Of the many subjects identified in the report as items for further study the two most urgent and obvious would seem to be, firstly, a study on fatalities in which hypotheses derived from our study would be tested; and, secondly, studies in spinal injuries, both sprains of the cervical and lumbar regions in patients, and fractures of the cervical and thoracic regions in fatalities.

Although the study documents injuries, bed-stay and mortality, it has no information about time lost from work and permanent disability. If these were collected in a future similar study, it might help in an evaluation of the financial results of the legislation. Even with the data possessed, a costing evaluation would seem to be well worth while.

\section{POINTS RAISED IN OPEN DISCUSSION}

Studies of the vehicles in which people have been injured indicate that seat-belt injuries are associated with the lower ISS values. When a car is impacted from the side and 'intrusion' occurs, higher ISS values are encountered.

A supplementary study at the Royal Victoria Hospital, Belfast, found that over $60 \%$ of people who report to hospital after a car accident have a sore neck at some stage. Of these one third are still experiencing symptoms from the neck one year later. The seat-belt study has clearly underreported this problem as the onset of symptoms from a 'neck sprain' is often delayed. 